\title{
THE INFLUENCE OF SELF-EFFICACY AND SOCIAL SUPPORT TOWARD SELF-REGULATION ON TRADITIONAL DANCERS
}

\author{
Agia Rahmah \\ Agiarahmah23@gmail.com \\ Anggota HIMPSI Jakarta
}

\author{
Gazi \\ gazi@uinjkt.ac.id \\ Fakultas Psikologi UIN Syarif \\ Hidayatullah Jakarta
}

\begin{abstract}
Dancers often feel things that could affect the movement of a dance as on when we get emotion dancer disturbances often unstable, a lack of concentration when dancers perform thus reducing penghayatan to motion in a dance and the importance of a proper partnership between dancer (if in one team). Penelitian aims to understand is there the influence of self-efficacy (initiative, Effort, and persistence) and social support (guidance, reassurance of worth, social integration, attachment, nurturance, and reliable alliance) against regulations themselves and traditional dancers. This study using methods of multiple regression analysis as the proportion of respondents as many as 201 members of traditional dance studio. A measuring instrument used was the self-regulation questionnaire, general self-efficacy scale (gses-12), the social provision scale. The results of the hypothesis minor show a variable that has the influence of a significant impact on regulations self is effort, reassurance of worth, social integration, attachment, and nurturance.
\end{abstract}

Keywords: self-regulation, self-efficacy, social support, traditional dancer.

\begin{abstract}
Abstrak
Penari sering merasakan hal-hal yang dapat mempengaruhi gerakan dari sebuah tarian seperti pada saat tampil gejolak emosi penari sering tidak stabil, kurangnya konsentrasi penari disaat tampil sehingga mengurangi penghayatan terhadap gerakan dalam sebuah tarian dan pentingnya kerjasama yang baik antar penari (jika dalam satu tim). Penelitian ini bertujuan untuk mengetahui apakah ada pengaruh self efficacy (initiative, effort, dan persistence) dan dukungan sosial (guidance, reassurance of worth, social integration, attachment, nurturance, dan reliable alliance) terhadap regulasi diri penari tradisonal. Penelitian ini menggunakan metode multiple regression analysis dengan responden sebanyak 201 anggota sanggar tari tradisional. Alat ukur yang digunakan adalah The self regulation questionnaire, General self efficacy scale (GSES-12), The social provision scale. Hasil uji hipotesis minor menunjukkan variabel yang memiliki pengaruh yang signifikan terhadap regulasi diri ialah effort, reassurance of worth, social integration, attachment, dan nurturance.
\end{abstract}

Kata kunci: regulasi diri, self efficacy, dukungan sosial, penari tradisional 


\section{PENDAHULUAN}

Saat ini kegiatan tari, khususnya tari tradisional mulai marak dipresentasikan diberbagai kalangan usia. Menari yaitu melakukan gerak tari yang dihasilkan dari perpaduan antara gerak tubuh dan irama musik pengiring tarian. Integrasi gerak dan irama musik ditunjang besar oleh aspek emosi. Suatu sanggar tari biasanya akan menampilkan tarian, terlepas dari apakah penari itu professional ataupun amatir (Langer, 2011).

Pada saat pertunjukkan atau pementasan, penari sering merasakan hal- hal yang dapat mempengaruhi gerakan dari sebuah tarian seperti pada saat tampil gejolak emosi penari sering tidak stabil, kurangnya konsentrasi penari disaat tampil sehingga mengurangi penghayatan terhadap gerakan dalam sebuah tarian dan pentingnya kerjasama yang baik antar penari (jika dalam satu tim). Regulasi diri menjadi penting karena sebagai penari tradisional hal tersebut harus mampu diatasi dengan baik tiap kali akan menampilkan sebuah pertunjukkan tari. Penari yang memiliki regulasi diri yang baik akan mampu mengontrol dirinya dan dapat menampilkan sebuah tarian yang bagus.

Pemahaman konsep tentang regulasi diri penting dalam pengembangan kemampuan prestasi pembelajar. Regulasi diri dipandang menjadi salah satu kunci pencapaian prestasi seseorang. Proses regulasi diri melibatkan keaktifan seseorang dalam menghasilkan pikiran, perasaan, tindakan, merencanakan serta terus-menerus mengadaptasikannya guna mencapai tujuan-tujuan (Zimmerman, 2011).

\section{KAJIAN TEORI}

Miller dan Brown (dalam Brown, Miller, dan Lawendowski, 1999) mendefinisikan regulasi diri sebagai kapasitas untuk merencanakan, mengarahkan dan memonitor perilaku seseorang dengan fleksibel untuk mengubah keadaan atau mencapai satu tujuan. Pengaturan diri adalah kemampuan untuk mengembangkan, menerapkan, dan secara fleksibel mempertahankan perilaku yang direncanakan agar dapat mencapai tujuan seseorang. Schunk (2012) mengatakan bahwa regulasi diri mengacu pada proses dimana individu secara sistematis mengarahkan pikiran-pikiran, perasaanperasaan, dan tindakan-tindakan kepada pencapaian tujuan.

Menurut Zimmerman dan Martinez-Pons (1990) dalam proses belajar, seorang individu yang belajar dengan regulasi diri akan memperoleh prestasi belajar yang baik, bertanggung jawab, dan tahu cara belajar yang efisien. Namun seorang remaja sangat jarang memiliki regulasi diri yang tepat dengan lingkungan sekitarnya, apalagi untuk bisa menciptakan lingkungan sosial dan fisiknya seimbang dalam berakitivitas, karena banyak faktor yang mempengaruhi dalam melakukan regulasi diri. Sama hal nya yang dikemukakan oleh Santrock (dalam Rachmah, 2015) regulasi diri dalam belajar yang baik akan membantu seseorang dalam memenuhi berbagai tuntutan yang dihadapinya.

Regulasi diri dipengaruhi oleh banyak faktor, salah satunya ialah self efficacy, seperti yang dikatakan oleh Zimmerman (2011) bahwa regulasi diri berhubungan secara positif dengan self efficacy. Seseorang yang mempunyai self efficacy yang tinggi maka regulasi dirinya juga tinggi, dan begitupun sebaliknya. Menurut 
Schultz (2005) self-efficacy ang tinggi dapat mengurangi rasa takut, mempertinggi aspirasi, mudah memecahkan suatu masalah dan mampu berfikir analitik. Berbeda dengan individu yang tidak memiliki self-efficacy yang tinggi, yang ada dipikiran mereka hanya sebuah kegagalan.

Salah satu faktor lain yang mempengaruhi regulasi diri adalah lingkungan sosial (Zimmerman, 1990). Menurut Zimmerman (1990) dalam teori sosial kognitif terdapat tiga hal yang mempengaruhi seseorang sehingga melakukan regulasi diri, yakni individu, perilaku, dan lingkungan. Faktor individu meliputi pengetahuan, tujuan yang ingin dicapai, kemampuan metakognisi serta efikasi diri. Faktor perilaku meliputi behavior self-reaction, personal self-reaction serta environment self-reaction. Pada faktor lingkungan dapat berupa lingkungan fisik maupun lingkungan sosial, baik lingkungan keluarga, lingkungan sekolah, lingkungan pergaulan dan lain sebagainya. Salah satu yang dapat mempengaruhi regulasi diri dalam faktor lingkungan sosial adalah dukungan sosial.

Menurut Johnson dan Johnson (1991) pentingnya dukungan sosial dengan pekerjaan akan meningkatkan produktivitas, meningkatkan kesejahteraan psikologis, dan penyesuaian diri dengan memberikan rasa memiliki, memperjelas identitas diri, menambah harga diri serta mengurangi stress, meningkatkan dan memelihara kesehatan fisik serta pengelolaan terhadap stress dan tekanan.

\section{METODE PENELITIAN}

\section{Populasi, sampel dan teknik pengambilan sampel}

Dalam penelitian ini yang dijadikan populasi adalah anggota Sanggar Tari Ratih Ayu. Jumlah sampel dalam penelitian ini sebanyak 201 sampel. Teknik sampling pada penelitian ini bersifat non probability sampling yaitu teknik pengambilan sampel secara sengaja sesuai dengan persyaratan sampel atau kriteria yang telah ditentukan. Dimana peluang terpilihnya setiap responden anggota populasi tidak dapat dihitung.

\section{Instrumen penelitian}

Instrumen pengumpulan data dalam penelitian ini yaitu:

1. Skala Regulasi diri

Alat ukur Regulasi diri diadaptasi dari skala Self Regulation, yaitu The Selfregulation Questionnaire berdasarkan dimensi-dimensi regulasi diri menurut teori Miller dan Brown (Brown, Miller, \& Lawendowski, 1999), yaitu receiving, evaluating, triggering, searching, formulating, implementing, \& assessing Instrumen yang asli berbahasa Inggris kemudian diterjemahkan ke dalam bahasa Indonesia. Skala aslinya berbentuk skala Likert dengan rentang lima poin yang kemudian penulis modifikasi menjadi rentang skala empat poin, yaitu dari SS (Sangat Setuju), S (Setuju), TS (Tidak Setuju) dan STS (Sangat Tidak Setuju).

\section{Skala Self-efficacy}

Alat ukur self-efficacy yang digunakan dalam penelitian ini adalah alat ukur General Self- Efficacy Scale (GSES-12) yang dikembangkan oleh Bosscher dan Smit (1998). Alat ukur ini mengukur 3 dimensi yaitu effort, initiative, dan 
persistence. Dikarenakan semua item di dalam General Self-Efficacy Scale (GSES-12) itu telah mengalami revisi dari General Self-Efficacy Scale sebelumnya. Sehingga 5 dari 17 item telah dikeluarkan dari GSES, karena kata-kata yang ambigu dan berkorelasi rendah. Instrumen yang asli berbahasa Inggris kemudian diterjemahkan ke dalam bahasa Indonesia. Skala aslinya berbentuk skala Likert dengan rentang tujuh poin yang kemudian penulis modifikasi menjadi rentang skala empat poin yaitu dari SS (Sangat Setuju), S (Setuju), TS (Tidak Setuju) dan STS (Sangat Tidak Setuju).

\section{Skala Dukungan Sosial}

Dalam penelitian ini, penulis mengukur dukungan sosial dengan menggunakan alat ukur yang diadaptasi dari Weiss (dalam Cutrona, 1987) yang mengemukakan adanya 6 dimensi dukungan sosial yang disebut sebagai "The Social Provision Scale". Adapun dimensi-dimensi tersebut adalah dukungan sosial (guidance, reassurance of worth, social integration, attachment, nurturance, dan reliable alliance). Skala ini terdiri dari 24 item dengan model Likert. Dalam penelitian ini, penulis menggunakan rentang skala empat poin, yaitu dari SS (Sangat Setuju), S (Setuju), TS (Tidak Setuju) dan STS (Sangat Tidak Setuju).

\section{HASIL PENELITIAN}

\section{Hasil Uji Hipotesis}

\section{Tabel 1}

Analisis Regresi

\begin{tabular}{llllll}
\hline Model & $\mathrm{R}$ & $\begin{array}{l}R \\
\text { Square }\end{array}$ & $\begin{array}{l}\text { Adjusted } R \\
\text { Square }\end{array}$ & $\begin{array}{l}\text { Std. Error of } \\
\text { Estimate }\end{array}$ & the \\
\hline 1 & $.878^{\mathrm{a}}$ & .771 & .760 & 4.81414 & \\
\hline
\end{tabular}

Berdasarkan tabel di atas, didapatkan proporsi varians dari intensi partisipasi pemilu yang dijelaskan semua independen variabel adalah sebesar $77.1 \%$, sedangkan $22.9 \%$ sisanya dipengaruhi oleh variabel lain di luar penelitian ini.

Tabel 2

Anova Signifikasi Pengaruh Keseluruhan IV terhadap DV

\begin{tabular}{lccccl}
\hline \multicolumn{1}{c}{ Model } & Sum of Squares & Df & Mean Squae & F & Sig. \\
\hline Regressi on & 14881,386 & 9 & 1653,487 & 71,345 & $.000 \mathrm{~b}$ \\
Residual & 4426,60 & 191 & 23,176 & & \\
Total & 19307,989 & 200 & & & \\
\hline
\end{tabular}

Diketahui bahwa nilai signifikansi lebih kecil $(\mathrm{p}<0.05)$, maka hipotesis nihil yang menyatakan tidak ada pengaruh yang signifikan seluruh independent variable terhadap dependent variable, yaitu regulasi diri ditolak. Artinya, ada pengaruh yang signifikan dari self-efficacy (initiative, effort, dan persistence) dan dukungan sosial (guidance, reassurance of worth, social integration, attachment, nurturance, dan reliable alliance) terhadap regulasi diri. 
Tabel 3

Koefisien Regresi

\begin{tabular}{|c|c|c|c|c|}
\hline \multirow[t]{2}{*}{ Model } & \multicolumn{2}{|c|}{ Unstandardized Coefficients } & \multirow{2}{*}{$\frac{\text { Standardized Coef }}{\text { Beta }}$} & \multirow[t]{2}{*}{$\mathbf{t}$} \\
\hline & $\mathrm{B}$ & $\mathrm{SE}$ & & \\
\hline (Consta nt) & -11.810 & 2.821 & & -4.187 \\
\hline Initiative & -.001 & .043 & -.001 & -.014 \\
\hline Effort & .176 & .062 & .154 & 2.817 \\
\hline Persist ence & .046 & .133 & .043 & .345 \\
\hline Guidance & .134 & .083 & .112 & 1.616 \\
\hline Reassurance of worth & .294 & .128 & .246 & 2.303 \\
\hline Social integration & .587 & .102 & .485 & 5.757 \\
\hline Attachment & .232 & .055 & .214 & 4.211 \\
\hline Nurturance & -.314 & .145 & -.271 & -2.176 \\
\hline Reliable alliance & .083 & .056 & .084 & 1.815 \\
\hline
\end{tabular}

(*signifikan)

Dapat disampaikan persamaan regresi sebagai berikut:

Regulasi Diri $=-11.810-0.001$ (initiative $)+0.176($ effort $)+0.046$ (persistence) + 0.134 (guidance) +0.294 (reassurance of worth) +0.587 (social integration) +0.232 (attachment) -0.314 (nurturance) +0.083 (reliable alliance).

Koefisien regresi yang dihasilkan signifikan pengaruhnya terhadap regulasi diri dan sebaliknya. Dari hasil di atas, koefisien regresi effort, reassurance of worth, social integration, attachment, dan nurturance memiliki pengaruh yang signifikan, sedangkan sisanya tidak.

\section{Proporsi varian}

1. Variabel initiative memberikan sumbangan sebesar $11.9 \%$ terhadap regulasi diri.

2. Variabel effort memberikan sumbangan sebesar $34.6 \%$ terhadap regulasi diri.

3. Variabel persistence memberikan sumbangan sebesar $9.4 \%$ terhadap regulasi diri.

4. Variabel guidance memberikan sumbangan sebesar $2.6 \%$ terhadap regulasi diri.

5. Variabel reassurance of worth memberikan sumbangan sebesar $5.1 \%$ terhadap regulasi diri.

6. Variabel social integration memberikan sumbangan sebesar $10.1 \%$ terhadap regulasi diri.

7. Variabel attachment memberikan sumbangan sebesar $2.3 \%$ terhadap regulasi diri.

8. Variabel nurturance memberikan sumbangan sebesar $0.6 \%$ terhadap regulasi diri.

9. Variabel reliable alliance memberikan sumbangan sebesar $0.4 \%$ terhadap regulasi diri.

\section{KESIMPULAN DAN DISKUSI}

\section{Kesimpulan}

Berdasarkan hasil analisis data penelitian maka dapat disimpulkan bahwa ada pengaruh yang signifikan dari self-efficacy (initiative, effort, dan persistence) dan dukungan sosial (guidance, reassurance of worth, social integration, attachment, nurturance, dan reliable alliance) terhadap regulasi diri penari tradisonal.Dari hasil 
analisis regresi didapatkan bahwa regulasi diri dipengaruhi oleh keseluruhan independent variable tersebut sebesar $77,1 \%$.

Hasil penelitian ketika dilihat dari koefisien regresi menghasilkan kesimpulan bahwa hanya ada lima dimensi yang berpengaruh signifikan terhadap regulasi diri. Variabel self-efficacy yang memberikan pengaruh signifikan terhadap regulasi diri adalah dimensi effort, dan variabel dukungan sosial yang memberikan pengaruh yang signifikan terhadap regulasi diri adalah reassurance of worth, attachment, social integration, dan nurturance. Sedangkan variabel self-efficacy yaitu dimensi initiative dan persistence dan variabel dukungan sosial yaitu dimensi guidance, dan reliable alliance tidak memberikan pengaruh yang signifikan terhadap regulasi diri.Hasil penelitian mengungkap lebih dari 70 persen penari tradisional memiliki regulasi diri yang tinggi. Artinya penari tersebut memiliki kemampuan dalam menangani pikiran, perasaan, dan tindakan agar dapat terungkap dengan tepat atau selaras, sehingga tercapai keseimbangan dalam diri penari tersebut untuk menampilkan suatu tarian dengan baik.

Selanjutnya, penelitian ini bertujuan untuk melihat variabel yang mempengaruhi regulasi diri penari tradisional. Berdasarkan hasil penelitian yang telah dipaparkan pada bab 4, diketahui bahwa dari sembilan variabel independen yang diteliti ternyata hanya lima variabel yang mempengaruhi regulasi diri secara signifikan. Variabel tersebut adalah effort, reassurance of worth, attachment, social integration, dan nurturance.

\section{Diskusi}

Berdasarkan hasil penelitian variabel self-efficacy dimensi yang memberikan pengaruh signifikan terhadap regulasi diri adalah effort. Dapat diartikan semakin tinggi tingkat effort yang dialami penari maka semakin tinggi pula regulasi dirinya. Effort juga menunjukkan siginifikansi terhadap regulasi diri, hal ini berarti seorang penari berusaha dalam meyempurnakan perilaku nya sehingga ia memiliki keyakinan dapat menghadapi suatu tantangan yg mudah maupun sulit. Dimana penari harus mampu melakukan penghayatan terhadap gerakan atau tarian, yang merupakan kesediaan penari untuk berusaha dalam menyempurnakan tarian nya atau dalam latihannya, dan siap menghadapi segala tantangan.

Hal ini senada dengan penelitian yang dilakukan oleh Zimmerman dan Pons (1990) yang menemukan bahwa adanya pengaruh self-efficacy terhadap regulasi diri. Penari tradisional yang memiliki effort yang tinggi akan membuat para penari tradisional memiliki regulasi diri yang tinggi juga. Tarian sebagai sarana interaksi sosial, dapat dilihat dari dua arah. Pertama, tarian sebagai sarana interaksi sosial antara penari. Kedua, tarian digunakan sebagai alat untuk mencapai tujuan interaksi sosial. Maka dari itu interaksi sosial secara signifikan mempengaruhi regulasi diri penari tradisional.

Dari variabel dukungan sosial yang mempunyai pengaruh yang signifikan yaitu social integration, reassurance of worth, attachment dan nurturance Reassurance of Worth juga menunjukkan signifikansi terhadap regulasi diri, hal ini berarti seorang penari mendapatkan pengakuan atas kemampuan keahlianya, serhingga individu merasa dihargai dan mendapat penghargaan dari orang lain atau lembaga. Social integration mempunyai pengaruh yang signifikan, hal ini berarti 
seorang penari memperoleh perasaan memiliki tim untuk saling berinteraksi, sehingga dapat dalam berbagi minat, perhatian, bahkan bisa untuk menghilangkan perasaan cemas disaat akan perform.

Dalam hasil wawancara dengan penari remaja, penari tersebut sangat membutuhkan interaksi yang baik dengan sesama tim nya, karena dengan berinteraksi penari tersebut bisa lebih untuk terbuka, jujur, dan tidak sungkan untuk meminta diajari apabila ada tarian yang tidak bisa oleh salah satu anggota tari sehingga bisa belajar atau berlatih bersama. Dengan berinteraksi mereka bisa menyesuaikan diri, saling tukar pikiran atau informasi, saling memberikan pendapat, saling memberikan perasaan yang positif, saling berbagi minat, sehingga bisa bekerja sama dengan baik dalam satu tim.

Setiap tim penari memiliki berbagai macam konflik karena sebuah perbedaan atau kesalahpahaman antara penari dengan penari, penari dengan tim, dan tim yang satu dengan tim yang lainnya akibat dari kurangnya interkasi sosial. Dapat disimpulkan interaksi sosial sangat penting bagi penari agar konflik tersebut bisa dihindari. Variabel Attachment juga menunjukkan signifikansi terhadap regulasi diri, hal ini berarti seorang penari kedekatan emosional sehingga dapat menimbulkan rasa aman dan nyaman sehingga akan menciptakan sikap yang tenang dan bahagia.

Berdasarkan hasil wawancara, dalam proses kelekatan antar penari yaitu proses pencarian kedekatan individu dengan individu lainnya, agar individu tersebut mampu bertahan dalam suatu tim, karena ia merasa terpenuhinya kebutuhan dari figur yang dilekatkan. Kedekatan emosional antar penari sangat penting, apalagi dalam suatu tim, karena kedekatan emosional yang erat antara dua individu, mengacu memiliki perasaan yang kuat satu sama lain dan melakukan banyak hal bersama untuk melanjutkan relasi dengan hangat.

Seorang individu yang mendapatkan kelekatan yang cukup, akan merasa dirinya aman, nyaman, dan lebih positif terhadap tim nya. Karena kelekatan juga disebut sebagai suatu ikatan yang intens, dan secara terus-menerus berakar dari fungsi perlindungan. Dalam hasil wawancara juga dijelaskan tentang kedekatan antar penari,apabila kedekatan sesama penari intens, mereka mampu membuat hubungan interpersonal dengan rasa saling percaya, dan bisa saling menghargai satu sama lain.

Hal ini sejalan dengan penelitian Shaver (1995) yang menyatakan bahwa individu membawa satu model kelekatan dalam hidup, model kelekatan inilah yang membimbing cara kita dalam berhubungan dengan orang lain, utamanya dalam hubungan tim atau kelompok.

Variabel nurturance juga menunjukkan signifikansi terhadap regulasi diri, hal ini berarti seorang penari merasakan perasaan akan saling membutuhkan. Hubungan interpersonal antar sesama penari sangatlah dibutuhkan, agar terhindar dari sikap egois masing- masing penari.

Selama proses penelitian dalam proses pengambilan data dan proses wawancara, baik dilakukan oleh peneliti pada saat sebelum mereka latihan tari, agar mereka bisa lebih fokus dan konsentrasi dalam wawancara dan dalam mengisi kuisioner. 


\section{DAFTAR PUSTAKA}

Adicondro \& Alfi. (2011). Efikasi diri, dukungan sosial keluarga dan self regulated learning pada siswa kelas viii. Skripsi. Yogyakarta: Universitas Ahmad Dahlan. 8, 18-27.

Alwisol. (2009). Psikologi kepribadian. Malang: UMM Press. 284-358.

Bandura, A. (1991). Social cognitive theory of self regulation. Stanford: Academic Press, Inc. 50, 248-287.

Boekaerts, M. Pintrich, P, \& Zeidner, M. (2000). Handbook of self regulation. California: Academic Press, Inc.

Bosscher, R. \& Smit, J. (1998). Confirmatory factor analysis of the general self efficacy scale. Behaviour research and theraphy. Amsterdam: Vrije Universiteit. 36, 339-343.

Brown, M. \& Lawendowski, L. (1999). The self regulation questionnaire. Innovations in Clinical Practice. Florida: Professional Resource Press. 17,281-291.

Cobb, R. (2003). The relationship between self regulated learning behavior and academic performance in web-based course. Disertation. Virginia: The Faculty of Virginia Polytechnic Institute and State University. 1-30.

Cutrona, C. \& Russel, D. (1987). The provisions of social relationships and adaptation to stress journal. Advances in Personal Relationships. California: JAI Press, Inc. 1,37-67.

Dewall, C. Baumeister, R. \& Stillman, T. (2007). Violence restaired: effect of selfregulation and it depletion on aggression. Journal of Experimental Sosial Psychology. Florida: Elsevier. 43, 62-76.

Feist, J. \& Feist, G. (2010). Teori kepribadian. Jakarta: Salemba Humanika. 219376.

Friedman, H. \& Schustack. M. (2008), Kepribadian teori klasik dan riset modern (3rd ed). Jakarta: Erlangga.

Johnson, D \& Johnson, F. (1991). Joining together: group theory and group skills (4th ed.). Englewood Cliffts: Prentice Hall Inc.

Kapliani, D. \& Ratna, S. (2008). Hubungan antara persepsi mahasiswa terhadap dukungan sosial dosen dengan regulasi diri dalam belajar. Naskah Publikasi. Yogyakarta: Fakultas Psikologi dan Ilmu Sosial Budaya Universitas Islam Indonesia. 1-23.

Lerek, F. (2015). Pengaruh motivasi belajar dan dukungan sosial teman sebaya terhadap regulasi diri pada mahasiswa yang kuliah sambil bekerja di fakultas ekonomi program studi ekonomi syariah universitas mulawarman samarinda. Skripsi. Samarinda: ejournal psikologi. 3, 441452.

Ormrod, J. (2008). Psikologi pendidikan membantu siswa tumbuh dan berkembang jilid dua (6th ed). Jakarta: Erlangga. 20-55.

Pintrich, P. (2004). A conseptual framework for assessing motivation and selfregulated learning in college students. Educational Psychology Review. New York: Springer Science. 16,396-399 
Rachmah, D. (2015). Regulasi diri dalam belajar pada mahasiswa yang memiliki peran banyak. Skripsi. Banjarmasin: Universitas Lambung Mangkurat. 42,61-77.

Saguni \& Amin (2014). Hubungan penyesuaian diri, dukungan sosial teman sebaya dan self regulation terhadap motivasi belajar siswa kelas akselerasi SMP Negri 1 Palu. Skripsi. Palu: IAIN Palu. 2,199-223.

Samaneh, H. (2013). The relationship between self-efficacy and self- regulation in vocabulary acquisition of Iranian EFL learners. Thesis: Journal of academic and applied. Sabzevar: Urmia University. 3, 20-31.

Santrock, J. (2003). Psychology: Essentials (2nd ed.). Texas: Mc Graw Hill.150487

Santrock, J. (2011). Masa perkembangan anak, jilid dua (11th ed.). Jakarta: salemba humanika. 225-504.

Schaie, K. \& Carstensen, L. (2006). Social structure, aging, and self regulation in the elderly. New York: Springer Publishing Company.

Schultz, D. \& Schultz, E. (2005). Theories of personality (8th ed.). Florida: Wadsworth Thomson. 415

Schunk, D. (2012). Learning theories teori - teori pembelajaran perspektif pendidikan (6th ed.). Carolina: Pearson.

Susanne, K. (2011). The foundations of art theraphy. Journal of the American Art Therapy Association. Michigan: Blackwell Publications. 16, 112-120

Susanto, H. (2006). Mengembangkan kemampuan self regulation untuk meningkatkan keberhasilan akademik siswa. Skripsi. Tasikmalaya.6471.

Tarmidi. \& Rambe, A. (2010). Korelasi antara dukungan sosial orangtua dan self directed learning pada siswa SMA. Jurnal Psikologi. Medan: Fakultas Psikologi Universitas Sumatera Utara. 37, 216-223.

Zahra, A (2014). Gambaran mengenai self regulation pada penari tradisional studi pada penari tradisional dari kelompok tari cioff Indonesia. Skripsi. Bandung: Universitas Padjajaran. 1-7.

Zimmerman, B. (1989). A social cognitive view of self-regulated academic learning. Journal of Educational Psychology. New york: American Psychological Association, Inc. 81, 329-339.

Zimmerman, B. (1990). Self regulated learning and academic achievment: an overview. Journal of Educational Psychology. New york: American Psychological Association, Inc. 25, 3-17.

Zimmerman, B. \& Martinez, P. (1990). Student differences in self-regulated learning: Relating grade, sex, and giftedness to self-efficacy and strategy use. Journal of Educational Psychology. New york: American Psychological Association, Inc. 82, 51-59.

Zimmerman, B. (2011). Influences on the Development of Academic Self Regulatory Processes. Handbook of Self-Regulation of Learning and Performance. London: Routledge 
The Influence of Self-Efficacy and Social Support Toward Self-Regulation an Traditional Dancers 